NBER WORKING PAPER SERIES

\title{
ARE THERE DIFFERENTIAL EFFECTS OF PRICE AND POLICY ON COLLEGE STUDENTS' DRINKING INTENSITY?
}

\author{
Jenny Williams \\ Frank J. Chaloupka \\ Henry Wechsler \\ Working Paper 8702 \\ http://www.nber.org/papers/w8702 \\ NATIONAL BUREAU OF ECONOMIC RESEARCH \\ 1050 Massachusetts Avenue \\ Cambridge, MA 02138 \\ January 2002
}

We gratefully acknowledge research support from the Robert Wood Johnson Foundation to Williams and Chaloupka through the ImpacTeen project and to Wechsler through the College Alcohol Study. We thank Erin Ruel for useful discussions. Excellent research assistance was provided by Dan Stone. The views expressed herein are those of the authors and not necessarily those of the National Bureau of Economic Research.

(C) 2002 by Jenny Williams, Frank J. Chaloupka and Henry Wechsler. All rights reserved. Short sections of text, not to exceed two paragraphs, may be quoted without explicit permission provided that full credit, including $(\mathrm{C}$ notice, is given to the source. 
Are There Differential Effects of Price and Policy on College Students' Drinking Intensity? Jenny Williams, Frank J. Chaloupka and Henry Wechsler

NBER Working Paper No. 8702

January 2002

JEL No. D12, I10

\begin{abstract}
$\underline{\text { ABSTRACT }}$
This paper investigates whether college students' response to alcohol price and policies differ according to their drinking intensity. Individual level data on drinking behavior, price paid per drink, and college alcohol policies come from the student and administrator components of the 1997 and 1999 waves of the Harvard School of Public Health (HSPH) College Alcohol Study(CAS). Students drinking behavior is classified on the basis of the number of drinks they typically consume on a drinking occasion, and the number of times they have been drunk during the 30 days prior to survey. A generalized ordered logit model is used to determine whether key variables impact differentially the odds of drinking and the odds of heavy drinking. We find that students who faced a higher money price for alcohol are less likely to make the transition from abstainer to moderate drinker and moderate drinker to heavy drinker, and this effect is equal across thresholds. Campus bans on the use of alcohol are a greater deterrent to moving from abstainer to moderate drinker than moderate drinker to heavy drinker.
\end{abstract}

Jenny Williams

University of Illinois at Chicago and University of Adelaide

Frank J. Chaloupka

University of Illinois at Chicago and NBER

fjc@uic.edu

Henry Wechsler

Harvard School of Public Health 


\section{INTRODUCTION}

A recent survey by the American Medical Association found that college binge drinking is among the top concerns of parents with college-aged children. ${ }^{1}$ This finding reflects the persistence of excessive alcohol use on college campuses despite the recent attention given to this issue by both the Federal government and college administrators. In addition to the much publicized alcohol related deaths on campus, heavy episodic drinking - or binge drinking - on campuses is associated with property damage, injuries arising from fights, unwanted sexual advances, and encounters with the police (Wechsler et al., 2000b, 1994). The adverse outcomes associated with heavy episodic drinking do not fall exclusively on those who engage in this behavior. Second hand effects of heavy episodic drinking include interruption of study, having to baby-sit a drunken student, and being the victim of physical or sexual assault (Wechsler et al., 2001a, 2001c, 1995b).

In addition to identifying the costs associated with excessive drinking by college students, empirical research has established that (as with the general population) college students' demand for alcohol responds to changes in the cost of alcohol use. Measures of the non-monetary costs of drinking such as access to alcohol, as well as the monetary costs of drinking have been examined in this literature. For example, Wechsler, et al. (2001b) find that campus bans on drinking (which limit access to alcohol) reduce the prevalence of drinking and frequent heavy episodic (binge) drinking. Chaloupka and Wechsler (1996) establish that the probability of participation in drinking and binge drinking is negatively related to the price of alcohol, and positively related to the number of licensed establishments within a mile of the college. Our research builds on this literature by investigating whether measures of the full price

\footnotetext{
${ }^{1}$ This survey was conducted by Penn, Schoen and Berland Associates Inc for the American Medical Association's Office of Alcohol and other Drug Abuse. The final results and summary of findings are available at http://www.stopcollegebingeing.com/.
} 
of alcohol have a differential impact on the likelihood of drinking in a moderate fashion compared to the likelihood of problem drinking.

This is an important question from a policy perspective because it brings into focus the fact that students with different drinking styles may not respond in the same way to the changes in the cost of alcohol. For example, bans on the use of alcohol on campus may have a greater impact on an abstainer's decision to drink moderately than on a moderate drinkers decision to drink heavily. An understanding of this issue can inform policy makers concerned with targeting specific drinking behaviors.

The rest of this paper is laid out as follows. In section 2 we describe the data used in the analysis. Section 3 presents the statistical model underlying our analysis, section 4 presents our results, and section 5 provides a discussion of the implications of our findings.

\section{DATA}

This study is based on the 1997 and 1999 waves of the Harvard School of Public Health College Alcohol Study. The Harvard School of Public Health College Alcohol Study first surveyed 140 colleges and universities in 1993. This was a nationally representative sample of 4year colleges and universities selected from the American Council on Education's list of accredited universities using probability proportionate to size sampling. One hundred thirty of the original colleges and universities participated in 1997 and 128 participated in the 1999 survey. The details of the sample and research design have been published elsewhere. (Wechsler et al. 1995a; Wechsler et al. 1998; Wechsler et al. 2000b).

In 1997 and 1999, questionnaires were initially mailed to students beginning at the end of February. Mailings were timed to avoid the period immediately preceeding and following spring break, so that students would be responding to behavior during a time when they were on 
campus. Student participation was voluntary and anonymous. To be included in this study, a school had to have a response rate of at least $50 \%$ in two of the three surveys and a rate of at least $40 \%$ in the third. A total of 119 schools located in 40 states were included in the analyses. The response rate varied among the 119 colleges that participated in the 1997 and 1999 surveys. In 1997 , response rates varied from $40 \%$ to $88 \%$ with an overall response rate of $60 \%$. The response rate for the 1999 sample varied from $40 \%$ to $83 \%$ with an overall response rate of $60 \%{ }^{2}$

The dependent variable in our analysis is students' drinking intensity. Using selfreported information on the number of drinks usually consumed and the number of times drunk in the 30 days prior to survey, we construct two measures of drinking intensity. The first is gender specific, based on the question "In the past 30 days, on the occasions when you drank alcohol, how many drinks did you usually have?" We define the first measure of drinking intensity to be 0 if the student did not drink during this period (abstainer), 1 if the respondent is a male (female) who typically drank less than 5 (4) drinks (moderate drinker), and 2 if they usually drank 5 (4) or more drinks (heavy drinker). A drink was defined in the questionnaire as either a 12-oz bottle or can of beer, a 4-oz glass of wine, a 12-oz bottle or can of wine cooler, or a shot of distilled spirits (either straight or in a mixed drink). On the basis of this measure of drinking intensity, $32 \%$ of students were categorized as abstainers, $37 \%$ as moderate drinkers, and $31 \%$ as heavy drinkers.

\footnotetext{
${ }^{2}$ We examined potential bias introduced by non-responders. The response rates at each individual colleges were not associated with the binge drinking rate in both the 1997 and 1999 survey. The Pearson correlation is 0.002, $(\mathrm{P}=0.986)$ in 1997 survey and $0.03(\mathrm{P}=0.75)$ in the 1999 survey. In addition, a short form of the questionnaire including questions about alcohol use was sent to students in 1999 who did not respond to the full questionnaire. There was no significant difference in rates of past-year alcohol use for those that answered the short survey compared to those that responded to the entire questionnaire (Chi-square $=0.24 ; \mathrm{P}=0.63$ ). The same pattern of responses among different student subgroups is present in all three years of the study, as well as in other major studies of college alcohol use. The binge drinking rates in the CAS in all three survey years were almost identical to rates obtained by other studies using different sampling methodologies (Johnston et al., 1997; Presley, 1996; Douglas, 1997).
} 
The second measure is based on the question "In the past 30 days, how often did you drink enough to get drunk?" We define this measure of drinking intensity as 0 if the respondent did not drink in the past 30 days (abstainer), 1 if they drank but did not get drunk or got drunk 13 times (moderate drinker), and 2 if they got drunk more often (heavy drinker). On the basis of this measure of drinking intensity, $32 \%$ of students were categorized as abstainers, $47 \%$ as moderate drinkers, and $21 \%$ as heavy drinkers. Drunk was defined to mean unsteady, dizzy or sick to your stomach.

The full price of alcohol consumption is captured using a college level measure of the price paid for a single alcoholic beverage, the proportion of drinkers who usually paid a fixed fee for all they could drink, the proportion of students paying by the drink who report they usually pay nothing, and campus level variables related to access and opportunity to use. The college level measure of price is based on the question: "How much do you typically pay for one alcoholic drink"? The response categories are: "Nothing, I do not drink", "Nothing, it is typically free”, "less than \$0.50", "between \$0.51 and \$1.00”, "between \$1.01 and 2.00”, “between \$2.01 and 3.00”, “\$3.01 or more”, "I pay a set fee for all I can drink”.

Those who report not usually paying for their drinks are an interesting group, comprising mostly females under the age of 21 , who are less likely to drink heavily than their peers who pay for drinks. The fact that the non-paying group is less likely to drink heavily suggests that there are non-monetary costs associated with accepting drinks. As these costs are unmeasured, we separate out the zero price observations from the non-zero price observations. The college level price for a single alcoholic drink is constructed by taking the midpoint of the price paid categories and averaging non-zero reported prices for all students within a college. This represents the average price paid (in dollars) by drinkers who pay (a positive amount) per drink 
for the college. We control for students who report that they usually pay nothing by calculating the college level proportion of drinkers who do not usually pay a set fee and who usually pay nothing.

About $4 \%$ of students report usually paying a fixed fee for all they can drink. Since paying a fixed fee means that the marginal cost of each drink after the first is zero, we would expect that the number of drinks consumed under this pricing scheme, and hence the probability of heavy drinking, would be greater than if there was a positive cost associated with each drink i.e. students paid by the drink. To account for this, we include a college level measure of the proportion of students who typically pay a fixed fee. The proportion of students who typically drink under these circumstances could be interpreted as a peer effect. Alternatively, this variable may measure the access students have to these types of events. Under either interpretation, we expect this variable to be positively related to the odds that an individual drinks and that he drinks heavily.

In addition to surveying students about their alcohol use, administrators from each college are also surveyed as part of the Harvard Study in order to obtain data on campus policies pertaining to alcohol use, and measures of access to alcohol within the campus neighborhood. An indicator for a campus ban on alcohol use and the number of off-campus outlets selling alcohol within a mile of campus are used to measure the non-monetary costs of alcohol use faced by students. A school is defined as banning the use of alcohol on campus if the administrator responds that alcohol use is prohibited for staff and students regardless of age, or that alcohol use is prohibited for all students regardless of age. Non-ban schools are those that answered that alcohol use is prohibited for everyone under 21 , or that they had no policy. To capture off- 
campus access to alcohol, we use the number of licensed outlets selling alcohol within a one mile radius of the school campus.

In addition to information on drinking, the student survey obtained detailed socioeconomic and demographic information that we use as controls in our analysis. These include: the age of the respondent (in years), age squared; an indicator for gender (male), race (White, Black, Asian, Native American), ethnicity (Hispanic, non-Hispanic), the religion that they grew up in (Catholic, Jewish, Moslem, Protestant, other religion, and no religion), parents' education (at least one parent completed college), and indicators of each parent's drinking behavior while the respondent was growing up (parent not present, abstainer, former drinker, moderate drinker, heavy drinker, problem drinker). The college level characteristics controlled for are: indicators for the college being a women's college, a historically black college, a commuter college, a small private college, a large private college, a large public campus, and a small public campus.

Several studies have found interdependencies in the demands for alcohol and cigarettes. To control for this, we include the price of cigarettes (measured in dollars) in the empirical models. The cigarette price is a state average cigarette price inclusive of tax for a pack of 20 cigarettes, based on the price of single cigarette packs, cartons and vending machine sales (Orzechowski and Walker, 2001). Finally, a set of regional indicators (West, South, Midwest, and Northeast) is included, in addition to an indicator for year of survey being 1997.

Descriptive statistics for the pooled sample of the 1997 and 1999 waves of the CAS, along with the price and policy variables are reported in Appendix 1. The price data are converted to constant 1999 dollars using the Consumer Price Index. After deleting observations with missing values for the control variables, and selecting the sample of undergraduates less 
than 25 years of age, we arrive at our sample size of 22,831 observations. The actual number of observations used in estimation is the number of observations for which we have non-missing data on the dependent variable.

\section{STATISTICAL MODEL}

The conceptual framework assumes a continuous underlying variable representing the intensity of drinking style. This intensity of drinking style is not directly observed, however, and we categorize individuals on the basis of the number of drinks they usually consume on a drinking occasion, or the number of times they were drunk in the past 30 days. This categorization results in a dependent variable that is discrete and ordinal in nature. In order for an individual to move from one category to the next, a threshold must be crossed. These thresholds can be thought of as hurdles of increasing difficulty that separate individuals into the increasingly intense drinking styles. ${ }^{3}$

In standard models applied to ordered categorical data, such as the ordered logit model, all explanatory variables other than the constant terms are assumed to have an equal effect on the probability of crossing each threshold. To illustrate, consider drinking intensity. There are two thresholds faced by students (the threshold between abstaining and moderate drinking and the threshold between moderate and heavy drinking), denoted $\gamma_{1}$ and $\gamma_{2}$. Suppose we have just one explanatory variable, school ban on alcohol ( $x=1$ if a ban is in place and 0 otherwise). Then, under the assumptions of the ordered logit model we have:

$$
\begin{aligned}
& \gamma_{1}=\beta_{0}^{1}+\beta_{1} x \\
& \gamma_{2}=\beta_{0}^{2}+\beta_{1} x
\end{aligned}
$$

\footnotetext{
${ }^{3}$ The discussion in this section draws heavily on Hedeker and Mermelstien (1998).
} 
Where $\beta_{0}^{\mathrm{j}}$ is the constant associated with threshold $\mathrm{j}=1,2$, and $\beta_{1}$ measures the effect of alcohol bans on the odds of crossing each threshold. By assumption, the effect of bans on the probability of crossing each threshold is the same. This type of equal effects model is used by Chaloupka and Wechsler (1996), who estimate an ordered probit model of intensity of drinking using data from the 1993 CAS.

It may be the case, however, that bans have a greater impact on raising the hurdle between abstaining and moderate drinking than between moderate and heavy drinking. In order to investigate the potentially differential role of bans on the probability of moving from abstainer to moderate drinker, and moderate drinker to heavy drinker we use the generalized ordered logit model. This model allows explanatory variables to have different effects on each threshold. Continuing we our previous example, the thresholds for moderate and heavy drinking in the generalized ordered logit model are given by:

$$
\begin{aligned}
& \gamma_{1}=\beta_{0}^{1}+\beta_{1}^{1} x \\
& \gamma_{2}=\beta_{0}^{2}+\beta_{1}^{2} x
\end{aligned}
$$

In this model, the odds ratio (OR) comparing the probability that a student at a ban school to a comparable student at a non-ban school crosses the threshold to moderate drinking is $\exp \beta_{1}^{1}$. The odds ratio for crossing the heavy drinking threshold for a student at a ban school compared to one from a non-ban school is $\exp \beta_{1}^{2}$. In contrast, in the basic ordered logit model, the odds ratio (OR) comparing respondents in ban schools with those in non-ban schools is the same for each threshold $\left(\exp \beta_{1}^{1}=\exp \beta_{1}^{2}=\exp \beta_{1}\right)$. A test of equality of the effect of covariates on the probability of crossing the moderate and heavy drinking thresholds can be carried out using a Wald test. 
It should be noted that because the sample design generating the CAS data involves first randomly sampling from the population of four-year colleges, and then drawing a random sample of students from each college, these data are likely to be clustered at the college level. Therefore, we relax the assumption of independent error terms and allow for a general form of clustering of observations at the college level in the following analysis. In particular, standard errors are calculated on the basis of the Huber/White estimator correcting for within school dependence.

\section{RESULTS}

The dependent variable in the following analysis takes on a value of zero for those who abstained from alcohol use in the past 30 days, 1 for moderate drinkers, and 2 for heavy drinkers. For the explanatory variables of interest, we report the odds ratio (i.e. $\exp \beta_{\mathrm{h}}^{\mathrm{j}}$ for the effect of variable $\mathrm{h}$ on the $\mathrm{jth}$ threshold), a $95 \%$ confidence interval for the point estimate of the odds ratio, p-values associated with each odds ratio, and the p-value for the Wald test of an equal effects of the explanator on the two thresholds. As the focus of this paper is on the effects of price and policy on drinking style, we present the results for theses variables only. Our findings with respect to demographic, socioeconomic, and family background variables are consistent with the results reported by Wechsler et al. (1995a, 1994) and Weitzman et al. (2000).

Table 1 contains results for the generalized ordered probit models of drinking style estimated over the full sample. We also estimate these models separately for the sub-sample of males and females (Table 2), students less than 21 years of age and at least 21 years of age (Table 3), and students who are white and not white (Table 4). The top half of each table reports the results for models that use the number of drinks consumed to measure drinking intensity, and the second half of the table reports results for which drinking intensity is measured using the 
number of times drunk. As most findings are robust with respect to the sample over which the model is estimated, the following discussion is based on the results in Table 1, noting differences that do arise.

Beginning with the effect of price, we find that (for both measures of drinking intensity) students that face higher prices for alcohol are less likely to make the transition from abstainer to moderate drinker and moderate drinker to heavy drinker. Also, the effect of price is not significantly different across the two thresholds. These results are robust with respect to the sample considered. The results in Table 1 indicate that on average, a one dollar increase in the price of a drink (its average is $\$ 2.17$ ) reduces the odds of crossing the threshold from abstainer to drinker by $33 \%$, and the odds of crossing the threshold from moderate to heavy drinker by a similar amount.

The prevalence of students who pay a set fee for entrance into all you can drink events has a statistically significant and equal effect on the odds of crossing both the drinking and heavy drinking thresholds. The effect is, however, quite small. The prevalence of students who report usually not paying for their drinks is found to have a small negative effect on the odds of crossing the drinking and heavy drinking threshold, having a greater impact on the odds of crossing the later threshold. Although the interpretation of this variable is not transparent, this result suggests that there are non-monetary costs/consequences associated with having someone else usually pay for you to drink.

When drinking intensity is measured by the number of drinks usually consumed on a drinking occasion, we find that bans have a significant effect on deterring the transition from abstainer to moderate drinker, but have no significant effect on the transition from moderate 
drinker to heavy drinker. ${ }^{4}$ This result is robust to the sub-sample considered, with the exception of the non-white sub-sample. On the basis of the estimates using the full sample, we find that the odds of crossing the drinking threshold are $26 \%$ smaller for a student who attends a school that bans alcohol consumption on campus compared to a student at a non-ban school. This result is confirmed using the measure of drinking intensity based on the number of times drunk for males, minors and non-whites. However using this second measure of drinking intensity, we find that college bans reduce the likelihood of both drinking and heavy drinking for the full sample, the sub-sample of females, students at least 21 years of age, and white students. For both measures of drinking intensity, a Wald test of equal effects of bans on the drinking and heavy drinking thresholds generally confirms that bans do not have the same effect on the two thresholds - bans have a larger effect on preventing drinking than preventing heavy drinking.

The final variable that we consider measures access to alcohol off campus, but within the college neighborhood. The number of licensed outlets within a mile radius of campus is found to have a small positive although generally insignificant association with the odds of drinking and heavy drinking. This result is somewhat sensitive to the sample and measure of drinking intensity considered. For example, using the number of drinks typically consumed to measure drinking intensity we find evidence that the odds of drinking are increasing in the number of outlets for females and whites. However, this variable has no impact on the odds of heavy drinking for these, or any other sub-sample. By comparison, the number of licensed outlets has the same (positive) effect on the odds of crossing both thresholds for females and whites if

\footnotetext{
4 This finding is consistent with Wechsler et al. (2001b) who find that among students who had consumed alcohol in the past 30 days, the prevalence of usually drinking in a heavy episodic manner is not significantly different at ban and non-ban schools.
} 
drinking intensity is measured by the number of occasions drunk. In all cases, however, the effect of this variable is small.

\section{DISCUSSION}

The results presented in this paper indicate that increasing the price of alcohol, which could be achieved by eliminating price specials and promotions, raising excise taxes, and eliminating fixed fee for all you can drink events on campus would lead to reductions in both moderate and heavy drinking by college students. Moreover both price and the prevalence of drinking at fixed fee events have an equal impact on drinking and heavy drinking. In contrast, campus bans on the use of alcohol, while reducing both moderate and heavy drinking, are more effective at reducing moderate drinking than heavy drinking.

A few cautions are important to note when interpreting these results. The measure of price used in this study is a college average of self-reported price per drink, and we have assumed that this measure of price is exogenous to the intensity of drinking decision. However, if the intensity of drinking affects the price of alcohol reported by students at a college, the estimated price effect is biased downwards (in absolute magnitude). A further potential source of endogeneity bias is the alcohol ban variable. If alcohol problems on campus lead to the college imposing the ban, then the effect of campus bans on drinking will be understated. Also, we have no information about the extent to which bans are enforced, and this must be borne in mind when interpreting the results. Finally, the above analysis suffers from the limitation that cross-sectional data are used to infer a longitudinal change in drinking intensity. Longitudinal data would be better suited to modeling transitions from abstainer to moderate drinker, and moderate to heavy drinker, as well as controlling for unobserved individual specific heterogeneity that impact these transitions. 
Despite these cautions, our finding that the probability that a student drinks or engages in heavy drinking is responsive to both monetary and non-monetary aspects of the full price of alcohol, is consistent with the majority of the existing literature. An exception is Chaloupka and Wechsler (1996), who examine the responsiveness of college students drinking and heavy drinking using the 1993 CAS. Because the 1993 survey does not ask about price paid for drinks, the authors match American Chamber of Commerce Research Associates (ACCRA) beer price information to college locations. The ACCRA beer price is the retail price for a six-pack of Budweiser or Miller Lite, and is collected quarterly for 120 cities. Using these data the authors find that drinking and heavy episodic drinking is price sensitive for the pooled sample of males and females, and the sub-sample of females. However, they fail to find any significant price effects for males. A possible explanation for the difference between our findings and those of Chaloupka and Wechsler is that, as noted by the authors, the ACCRA beer price data may not be a good measure for the prices actually paid when students by students, nor may they be reflective of actual prices faced in college towns not covered by the ACCRA data.

The significant and equal effect of price on reducing heavy and moderate drinking found in this research serves as further evidence that increasing the price of alcohol is an effective policy instrument for reducing excessive drinking by young adults. As with college bans on alcohol use, however, the economic cost of increased alcohol taxes and other policies that raise prices would not be born entirely by college students who engage in heavy drinking. That being said, a recent study of secondhand effects of college drinking experienced by nearby neighbors suggests that the benefits of reducing alcohol abuse by college students would also be enjoyed by the wider community (Wechsler et al. 20001c). 


\section{REFERENCES}

Chaloupka, FJ and Wechsler H. 1996. Binge Drinking in College: The Impact of Price, Availability, and Alcohol Control Policies. Contemporary Economic Policy 14: 112-124.

Douglas KA, Collins JL, Warren C, Kann L, Gold R, Clayton S, Ross JG, Kolbe LJ. Results from the 1995 National College Health Risk Behavior Survey. J Am Coll Health. 1997 Sep;46(2):55-66.

Hedeker, D. and Mermelstein, RJ. 1998. A Multilevel Thresholds of Change Model for Analysis of Stages of Change Data. Multivariate Behavioral Research. 33; 427-455.

Johnston LD, O'Malley PM, Bachman JG. National survey results on drug use from the Monitoring the Future Study, 1975-1995; Vol II, College students and young adults. US Department of Health and Human Services; NIH Publication number 98-4140;1997.

Orzechowski W, and Walker, R. 2001. Tax Burden on Tobacco. Arlington VA.

Presley CA, Meilman PW; Cashin JR and Lyerla R. 1996. Alcohol and Drugs on American College Campuses: Use, Consequences, and Perceptions of the Campus Environment, Vol IV: 1992-94. Carbondale, IL: Southern Illinois University.

Wechsler, H; Davenport A; Dowdall G; Moeykens B and Castillo S. 1994. Health and Behavioral Consequences of Binge Drinking in College: A National Survey of Students at 140 Campuses. Journal of the American Medical Association 272: 1672-1677.

Wechsler, H; Dowdall G; Davenport A, Castillo S. 1995a. Correlates of College Student Binge Drinking. American Journal of Public Health, 85:921-926.

Wechsler, H; Moeykens B; Davenport A; Castillo S; Hansen J. 1995b. The Adverse Impact of Heavy Episodic Drinkers on Other Students. Journal of Studies on Alcohol 56: 628-634.

Wechsler H, Dowdall GW; Maenner G; Gledhill-Hoyt J and Lee H. 1998. Changes In Binge Drinking And Related Problems Among American College Students Between 1993 And 1997. Results Of The Harvard School Of Public Health College Alcohol Study. Journal of American College Health; 47: 57-68.

Weitzman E and Wechsler H. Alcohol Use, Abuse, and Related Problems Among Children of Problem Drinkers".2000. Journal of Nervous and Mental Disease. 188:148-154.

Wechsler H, Kuo M, Lee H, and Dowdall G. 2000a. Environmental Correlates of Underage Alcohol Use and Related Problems of College Students. American Journal of Preventive Medicine, 19(1). 24-29.

Wechsler H., Lee JE; Kuo M; Lee H. 2000b. College Binge Drinking in the 1990s. A Continuing Problem: Results of the Harvard School of Public Health 1999 College Alcohol Study. Journal of American College Health 48199-210. 
Wechsler H., Lee JE; Nelson TF and Lee H. 2001a. Drinking Levels, Alcohol Problems and Secondhand Effects in Substance-Free College Residences: Results of a national study. Journal of Studies on Alcohol 62: 23-31.

Wechsler, H., Lee JE., Gledhill-Hoyt J and Nelson, TF. 2001b. Alcohol Use and Problems at Colleges Banning Alcohol: Results of a National Survey. Journal of Studies on Alcohol, 62: 133141

Wechsler H, Lee JE; Hall J; Wagenaar AC and Lee H. 2001c. Secondhand Effects of Student Alcohol Use Reported by Neighbors of Colleges: The Role of Alcohol Outlets. Social Science and Medicine, in press 
Table 1: Generalized Logit Model

Odds Ratio (OR) Estimates *

\begin{tabular}{|c|c|c|c|}
\hline & \multicolumn{3}{|c|}{ Full Sample } \\
\hline & OR1 & OR2 & $\begin{array}{l}\text { p-Value for } \\
\text { OR1=OR2 }\end{array}$ \\
\hline Average number of drinks consumed & \multicolumn{2}{|c|}{$N=19707$} & \\
\hline Price of alcohol & 0.673 & 0.589 & 0.161 \\
\hline $95 \% \mathrm{Cl}$ & {$[0.536,0.846]$} & {$[0.484,0.716]$} & \\
\hline $\mathrm{p}$-value & $(0.001)$ & $(0.000)$ & \\
\hline Percent of drinkers paying a fixed fee & 1.016 & 1.016 & 0.989 \\
\hline $95 \% \mathrm{Cl}$ & {$[1.004,1.028]$} & {$[1.007,1.026]$} & \\
\hline$p$-value & $(0.007)$ & $(0.001)$ & \\
\hline Percent of drinkers who usually don't pay & 0.991 & 0.977 & 0.000 \\
\hline $95 \% \mathrm{Cl}$ & {$[0.983,0.999]$} & {$[0.967,0.987]$} & \\
\hline p-value & $(0.033)$ & $(0.000)$ & \\
\hline Campus Ban on Alcohol Consumption & 0.742 & 0.903 & 0.001 \\
\hline $95 \% \mathrm{Cl}$ & {$[0.612,0.898]$} & {$[0.769,1.060]$} & \\
\hline$p$-value & $(0.002)$ & $(0.212)$ & \\
\hline Number of licensed outlets within a mile of campus & 1.016 & 1.003 & 0.135 \\
\hline $95 \% \mathrm{Cl}$ & {$[0.995,1.037]$} & {$[0.985,1.020]$} & \\
\hline$p$-value & $(0.147)$ & $(0.763)$ & \\
\hline Pseudo R2 & 0.0892 & & \\
\hline Number of times drunk & & & \\
\hline Price of alcohol & 0.682 & 0.612 & 0.215 \\
\hline $95 \% \mathrm{Cl}$ & {$[0.542,0.857]$} & {$[0.487,0.769]$} & \\
\hline$p$-value & $(0.001)$ & $(0.000)$ & \\
\hline Percent of drinkers paying a fixed fee & 1.018 & 1.017 & 0.844 \\
\hline $95 \% \mathrm{Cl}$ & {$[1.005,1.030]$} & {$[1.005,1.028]$} & \\
\hline p-value & $(0.005)$ & $(0.005)$ & \\
\hline Percent of drinkers who usually don't pay & 0.992 & 0.983 & 0.012 \\
\hline $95 \% \mathrm{Cl}$ & {$[0.983,1.000]$} & {$[0.973,0.993]$} & \\
\hline p-value & $(0.053)$ & $(0.001)$ & \\
\hline Campus Ban on Alcohol Consumption & 0.725 & 0.829 & 0.026 \\
\hline $95 \% \mathrm{Cl}$ & {$[0.597,0.881]$} & {$[0.711,0.966]$} & \\
\hline$p$-value & $(0.001)$ & $(0.016)$ & \\
\hline Number of licensed outlets within a mile of campus & 1.017 & 1.018 & 0.922 \\
\hline $95 \% \mathrm{Cl}$ & {$[0.995,1.039]$} & {$[0.999,1.037]$} & \\
\hline$p$-value & $(0.126)$ & $(0.066)$ & \\
\hline Pseudo R2 & 0.884 & & \\
\hline
\end{tabular}

*The odds ratios are defined in terms of $\mathrm{P}(\mathrm{Y}>=\mathrm{a}) / \mathrm{P}(\mathrm{Y}<\mathrm{a})$. Accordingly, the effect of a change in $\mathrm{x}_{\mathrm{k}}$ on the odds ratio is given by: $\exp \left(\Delta \mathrm{x}_{\mathrm{k}} \beta_{\mathrm{k}}\right)$ 


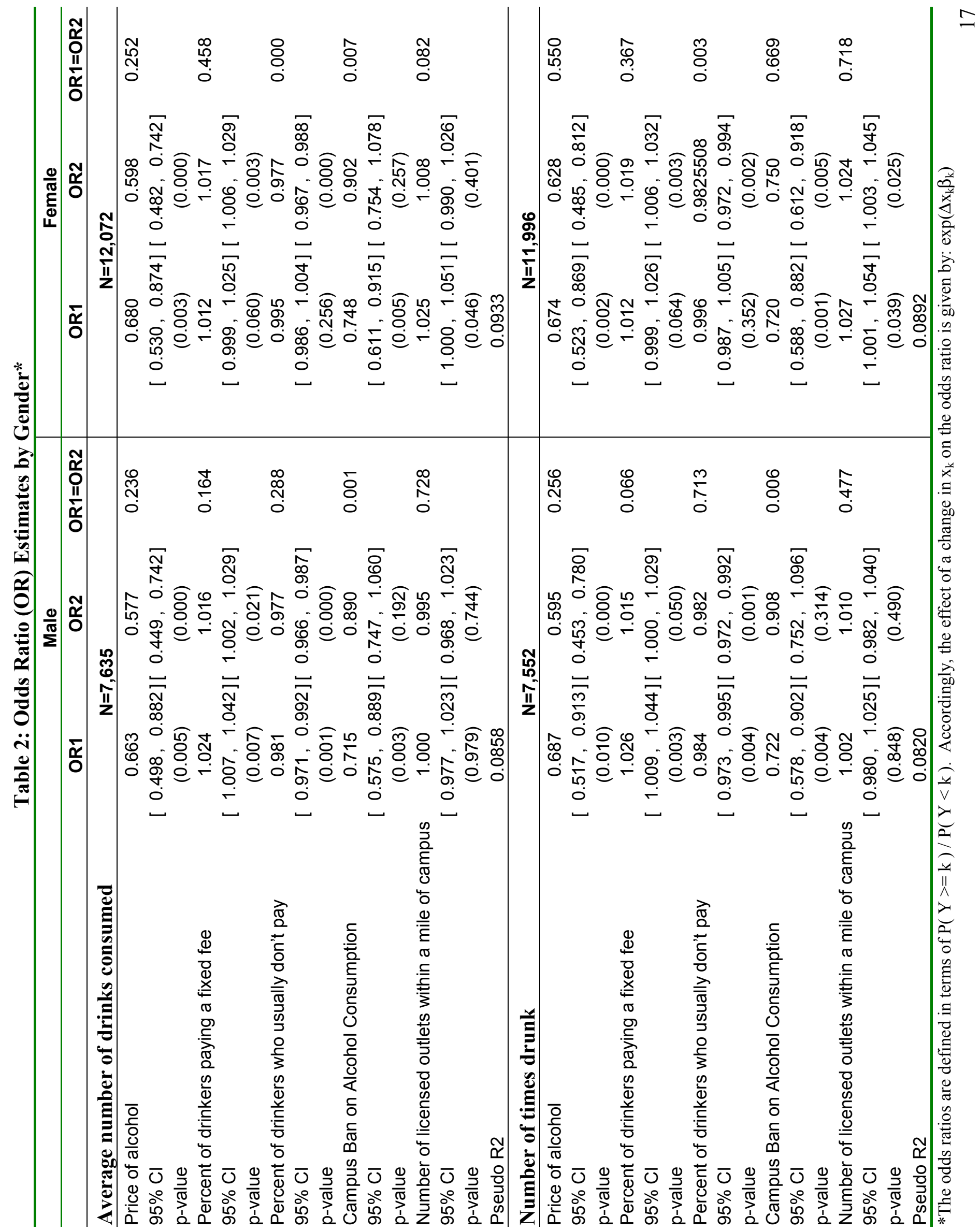




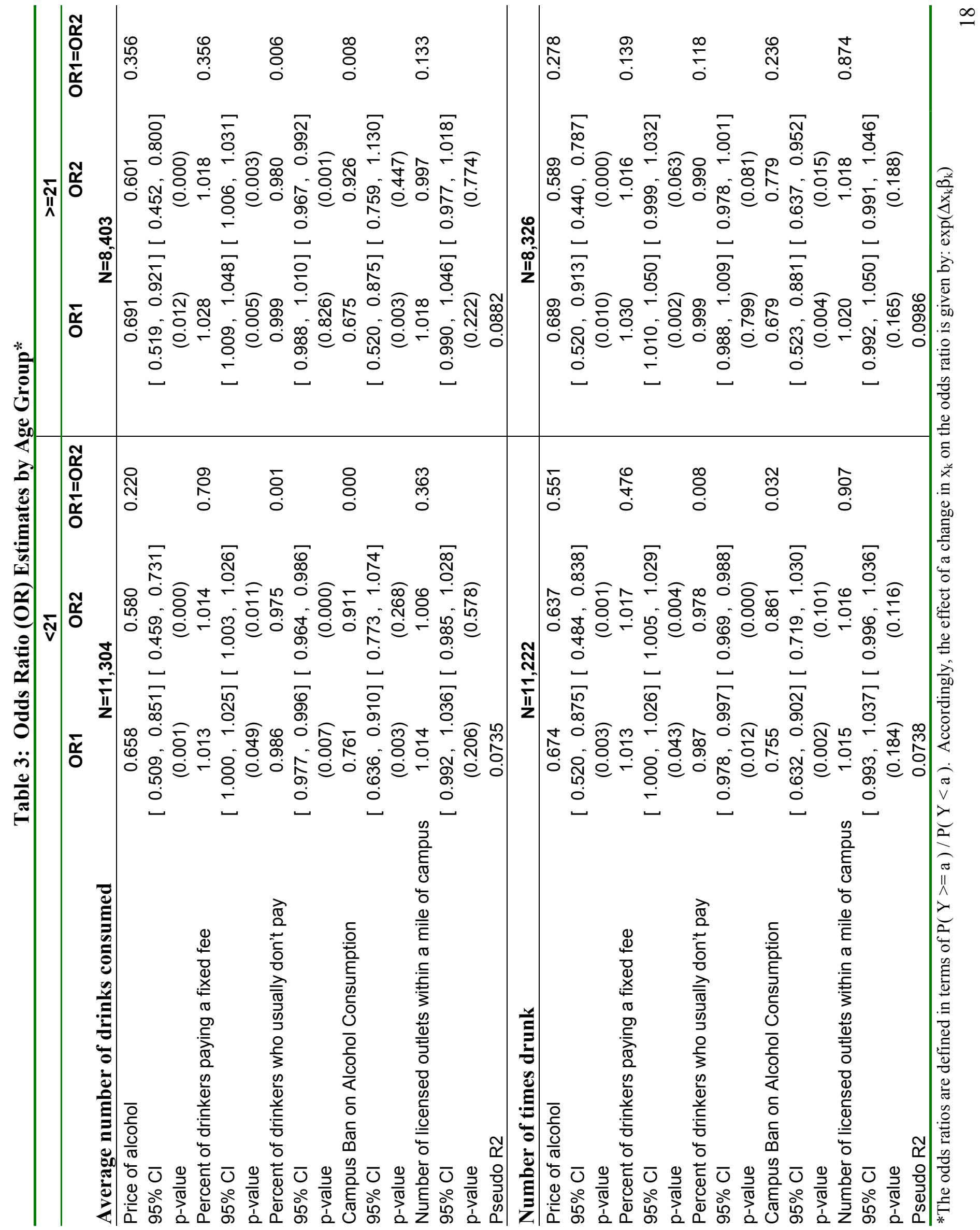




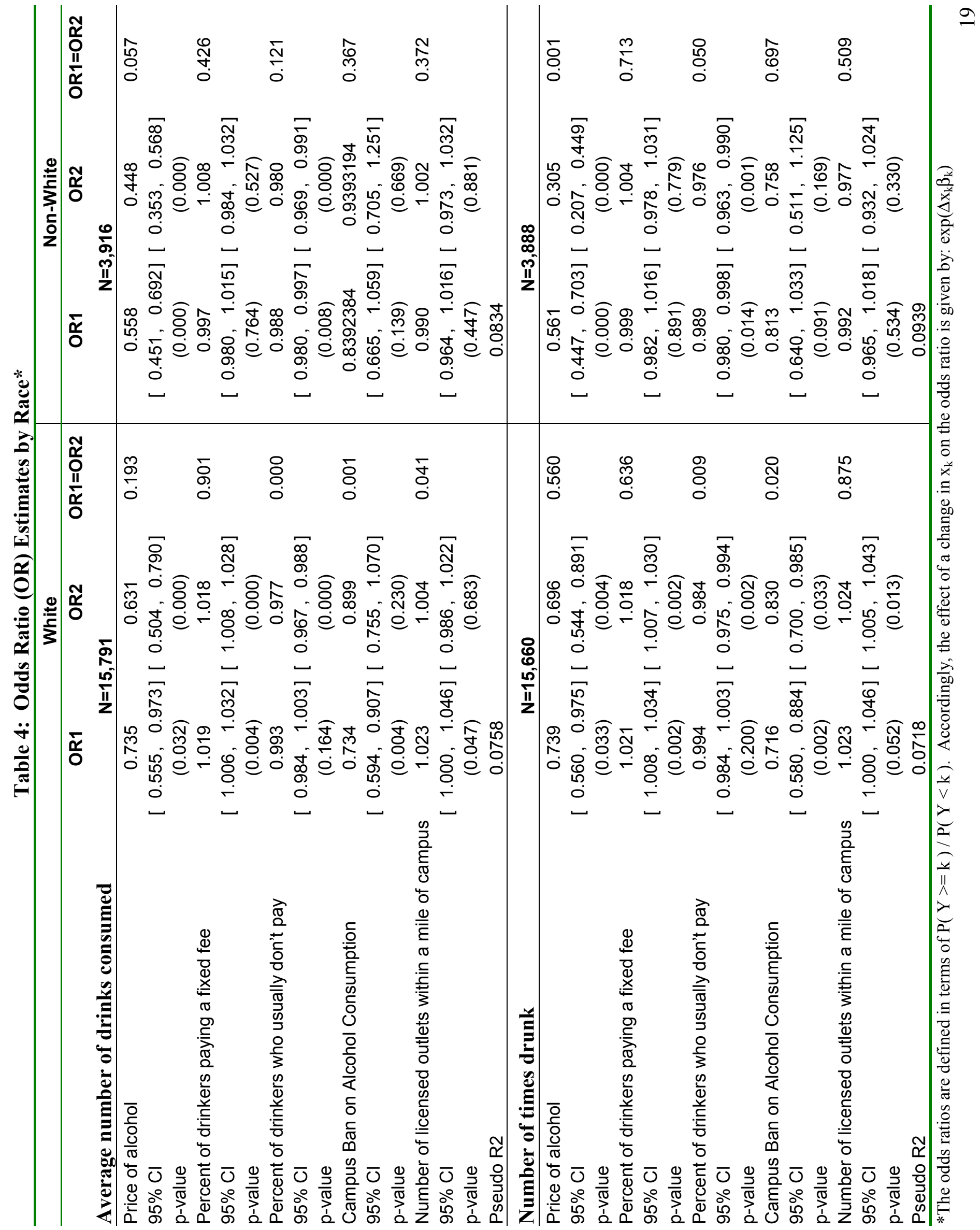


Appendix 1

Summary Statistics

\begin{tabular}{|c|c|c|c|c|}
\hline Variable & Mean & Std. Dev. & Min & Max \\
\hline average price per alcoholic drink (in \$1999) & 2.17 & 0.38 & 1.41 & 3.31 \\
\hline proportion of drinkers who pay a flat fee for all they can drink & 4.34 & 4.96 & 0 & 30.39 \\
\hline proportion of drinking students not paying a flat fee who usually pay nothing & 18.16 & 8.86 & 0 & 55.08 \\
\hline alcohol consumption banned on campus & 0.23 & 0.42 & 0 & 1 \\
\hline number of licensed outlets selling alcohol within a mile of campus & 7.09 & 3.45 & 0 & 10 \\
\hline cigarette price (in \$1999) & 2.55 & 0.55 & 1.62 & 3.60 \\
\hline Male & 0.39 & 0.49 & 0 & 1 \\
\hline Age & 20.29 & 1.56 & 15 & 24 \\
\hline Age squared & 414.21 & 64.31 & 225 & 576 \\
\hline Hispanic & 0.07 & 0.25 & 0 & 1 \\
\hline African American & 0.04 & 0.21 & 0 & 1 \\
\hline Asian & 0.08 & 0.27 & 0 & 1 \\
\hline Native American & 0.01 & 0.07 & 0 & 1 \\
\hline Other Race & 0.07 & 0.26 & 0 & 1 \\
\hline Raised Catholic & 0.37 & 0.48 & 0 & 1 \\
\hline Raised Jewish & 0.03 & 0.18 & 0 & 1 \\
\hline Raised Moslem & 0.01 & 0.09 & 0 & 1 \\
\hline Raised Protestant & 0.33 & 0.47 & 0 & 1 \\
\hline Raised other religion & 0.13 & 0.33 & 0 & 1 \\
\hline One parent completed college & 0.83 & 0.37 & 0 & 1 \\
\hline No father present & 0.02 & 0.15 & 0 & 1 \\
\hline Father former drinker & 0.02 & 0.16 & 0 & 1 \\
\hline Father infrequent drinker & 0.43 & 0.49 & 0 & 1 \\
\hline Father moderate drinker & 0.22 & 0.41 & 0 & 1 \\
\hline Father heavy drinker & 0.05 & 0.22 & 0 & 1 \\
\hline Father problem drinker & 0.05 & 0.21 & 0 & 1 \\
\hline No mother present & 0.01 & 0.07 & 0 & 1 \\
\hline Mother former drinker & 0.01 & 0.09 & 0 & 1 \\
\hline Mother infrequent drinker & 0.52 & 0.50 & 0 & 1 \\
\hline Mother moderate drinker & 0.09 & 0.29 & 0 & 1 \\
\hline Mother heavy drinker & 0.01 & 0.10 & 0 & 1 \\
\hline Mother problem drinker & 0.01 & 0.10 & 0 & 1 \\
\hline Womens' college & 0.05 & 0.22 & 0 & 1 \\
\hline African American College & 0.00 & 0.07 & 0 & 1 \\
\hline Commuter college & 0.11 & 0.32 & 0 & 1 \\
\hline Small private college & 0.11 & 0.31 & 0 & 1 \\
\hline Large private college & 0.16 & 0.37 & 0 & 1 \\
\hline Small public college & 0.16 & 0.37 & 0 & 1 \\
\hline SOUTH & 0.28 & 0.45 & 0 & 1 \\
\hline WEST & 0.16 & 0.37 & 0 & 1 \\
\hline MIDWEST & 0.32 & 0.47 & 0 & 1 \\
\hline yr97 & 0.51 & 0.50 & 0 & 1 \\
\hline
\end{tabular}

